\title{
BUILDING ENVELOPE AND ENERGY DEMAND IN RETROFITTING OFFICE
}

\author{
S. DARULA* , M. MALIKOVA \\ Institute of Construction and Architecture, Slovak Academy of Sciences, Dubravska cesta 9, SK-845 03 Bratislava 45, Slovakia \\ *E-mail: usarsdar@savba.sk
}

Building envelopes have a significant role in the protection of interiors against weather conditions. While wind, rain barriers and barriers against excessive heat gains were constructed from insufficient elements in the past, the current requirements for envelope functions are different. New materials and technologies allow for more complex design and evaluation of parameters in regard to the needs of occupants and economical interior performance.

This paper is focused on the daylighting solutions inside lit office space in which renovation of the lighting system is expected. Several retrofit scenarios based on window shading variations and lighting systems are investigated. Achieved results are evaluated from the point of view of energy demand. The integrative multi-platform tool, the Lighting Retrofit Adviser (LRA) is applied to calculate energy renovation preferences and to accept decision.

Keywords: daylighting, artificial lighting, visual environment, energy demand, retrofit

\section{Introduction}

Quality of the visual environment in offices depends on properties of building envelopes, space configuration, task requirements, placement of work places and access to daylight, electric lighting system and behaviour of occupants. There are many methods and computer programs for evaluation of daylighting and artificial lighting design, e.g. Relux, Velux Daylight Visualizer, EnergyPlus or Daysim, allowing quite precise simulation of various situations to be performed.

Existing systems for artificial lighting account for approximately $19 \%$ of the global electric energy consumption and it is assumed that this consumption will increase by more than $40 \%$, [Web 1]. Lighting systems with fluorescent lamps, scarcely with incandescent bulbs, were installed in office buildings in the past. In [Web 1] it was found that the distribution of light sources in office buildings consists of $73 \%$ fluorescent lamps, $7 \%$ compact fluorescent lamps, $12 \%$ incandescent, $7 \%$ halogen and $1 \%$ other sources. These findings indicate that for more efficient performance of lighting the reconstruction or retrofit lighting systems will be required in the future.

Architects and developers have the intention to improve visual environment in existing buildings, but reliable decision tools are generally missing. One such tool is available on [Web 2] which allows investigating energy and costs effects of built scenarios with various technologies.

\section{Materials and calculation methods}

A process in the primary decision stage requires not more precise information about possible applied technologies but relevant information about effectivity of assumed solutions. In the case of the retrofit lighting system the problem can be formulated as to how to remove an existing system and what is most effective for its replacement [2]. Generally, old lighting systems consist of classical fluorescent or incandescent sources [Web 1].

Retrofit scenarios should consider optical characteristics of new sources, daylight openings [3, 4], en-

This is an open-access article distributed under the terms of the Creative Commons Attribution-NonCommercial 4.0 International License (https://creativecommons.org/licenses/by-nc/4.0/), which permits unrestricted use, distribution, and reproduction in any medium for non-commercial purposes, provided the original author and source are credited, a link to the CC License is provided, and changes - if any - are indicated. 
Table 1. Description of sun protection and daylight management applied in scenarios

\begin{tabular}{|c|c|c|}
\hline Light source & Sun protection & Daylight management \\
\hline \multirow{3}{*}{ Incandescent } & No sun protection & No light management \\
\hline & Manually operated venetian blinds & \multirow{2}{*}{ Daylight depend controls } \\
\hline & Automatically operated venetian blinds & \\
\hline \multirow{3}{*}{ Halogen } & No sun protection & No light management \\
\hline & Manually operated venetian blinds & \multirow{2}{*}{ Daylight depend controls } \\
\hline & Automatically operated venetian blinds & \\
\hline \multirow{3}{*}{ CFL } & No sun protection & No light management \\
\hline & Manually operated venetian blinds & \multirow{2}{*}{ Daylight depend controls } \\
\hline & Automatically operated venetian blinds & \\
\hline \multirow{3}{*}{ LED } & No sun protection & No light management \\
\hline & Manually operated venetian blinds & \multirow{2}{*}{ Daylight depend controls } \\
\hline & Automatically operated venetian blinds & \\
\hline
\end{tabular}

ergy performance [5-7], investments [8] and labour costs. In the first decision step the energy savings with improvement of visual environment, i.e. sufficient illuminance, daylight access, colour rendering and lifetime of new artificial lighting system should by counted.

The present study is based on the evaluation of retrofit scenarios while achieved effects are compared to basic illumination situation created by incandescent luminaires as reference situation. Three technologies were used in built scenarios: halogen lamps, compact fluorescent lamps - CFL, and interior LED luminaires. Different situations with and without sun protection and management with and without daylight controls were considered (see Table 1). It is assumed that lighting systems of each scenario produce the comparable luminous flux (1) at the reference plane. Number of luminaires and light sources was calculated separately for each scenario to achieve this assumption.

Overall, 12 simple applicable scenarios of retrofit lighting systems in the offices oriented to 3 cardinal directions North, East or West and South were proposed, i.e. in total 36 scenarios. Tool Lighting Retrofit Adviser offers the same results for eastern and western orientation.

Luminous flux of each light source was calculated after formula

$$
\Phi=P \times \text { eff }[\mathrm{lm}],
$$

where $\Phi$ - luminous flux in $1 \mathrm{~m}, P$ - power in $\mathrm{W}$, eff luminous efficacy in $1 \mathrm{~m} / \mathrm{W}$.
Luminous flux and correlated colour temperature $C C T$ of light sources are very different and describe electric energy use and a quality of artificial light. In Table 2, values of luminous efficacy and CCT of sources used in this study are presented.

Table 2. Luminous efficacy and $C C T$ of applied light sources

\begin{tabular}{lcc}
\hline Light source & $\begin{array}{c}\text { Luminous } \\
\text { efficacy }[\mathrm{lm} / \mathrm{W}]\end{array}$ & $\begin{array}{c}\text { Correlated colour } \\
\text { temperature }[\mathrm{K}]\end{array}$ \\
\hline Incandescent bulb & 13.5 & 2700 \\
Halogen lamp & 15.0 & $2800-3400$ \\
$\begin{array}{l}\text { Compact fluorescent } \\
\text { lamps - CFL }\end{array}$ & 57.0 & $2700-5000$ \\
LED & 62.5 & $6500-7000$ \\
\hline
\end{tabular}

Score - strategy assessment method was used for evaluation of the proposed strategies. Two types of indicators, energy (energy demand) and quality of visual environment (correlated colour temperature) were quantified. The same importance is assumed for both indicators; therefore waiting factors were not applied. The quantification of scores for the scenario rating is presented in Table 3. The scenario with minimum score number is the best investigated alternative.

Retrofit of lighting system seems to be a simple problem, but when real technical conditions of existing luminaires and electricity system and standard requirements for visual tasks and quality of relevant spaces have to be taken into account, then a decision process can become complicated. This study presents

Table 3. Scores for assessment of scenarios

\begin{tabular}{lccccc}
\hline Description & Very good & Good & Moderate & Poor & Very poor \\
\hline Score & 1 & 2 & 3 & 4 & 5 \\
\hline
\end{tabular}


Table 4. Characteristics used in scenario investigations

\begin{tabular}{|c|c|}
\hline Characteristics & Description \\
\hline Surface reflections & Ceiling $50 \%$, walls $50 \%$, floor $10 \%$ \\
\hline Lighting concept & $\begin{array}{l}\text { Luminaires mounted in the ceiling, alternatively: - luminaires (incandescent, CFL, LED sources); } \\
\text { - downlights (halogen) }\end{array}$ \\
\hline Light direction & Direct down from ceiling \\
\hline Light shape & Rectangular luminaires on the grid \\
\hline Lamp type & Alternatively: - incandescent lamp; - halogen lamp; - CFL; - LED luminaire \\
\hline Optical system & $\begin{array}{l}\text { Alternatively: - cover out of clear glass or plastic (incandescent);- highly specular raster (CFL); } \\
\text { - prismatic cover (halogen and LED luminaire) }\end{array}$ \\
\hline Lamp ballast & $\begin{array}{l}\text { Alternatively: - with electronic ballast (CFL, LED luminaire); - without ballast (incandescent and } \\
\text { halogen lamps) }\end{array}$ \\
\hline Window layout & Wide \\
\hline Wall orientation & Alternatively: - North; - East; - South; - West \\
\hline Window size & Window to wall ratio (WWR) of $40 \%$ \\
\hline
\end{tabular}

methodology for built in retrofit scenarios based on the application of the free on the WWW operable tool Lighting Retrofit Adviser [Web 2, 11].

The compact office with $30 \mathrm{~m}^{2}$ floor area and single work places was selected. Variations of characteristics of office spaces and lighting management are documented in Table 4.

As reference situation an office proposed illuminated by 4 luminaires with 2 incandescent lamps, while each lamp has power $P=100 \mathrm{~W}$ and luminous flux $\Phi=1350 \mathrm{~lm}$, then the total installed power is $800 \mathrm{~W}$ and total luminous flux received by reference plane is $\Phi=10800 \mathrm{~lm}$. Proposed scenarios for decision contain alternative lighting systems consisting of:

- 24 pieces of compact fluorescent lamp CFL with power $P=8.75 \mathrm{~W}$ installed in four luminaires with the total installed power $210 \mathrm{~W}$,

- 20 halogen lamps with power $P=35 \mathrm{~W}$ of the total installed power is $700 \mathrm{~W}$ and grouped in four places in the ceiling,

- 8 luminaires with integrated LEDs of the total installed power $P=144 \mathrm{~W}$.

Table 5. Energy demand for lighting systems with incandescent and halogen lamps

\begin{tabular}{|c|c|c|c|c|c|}
\hline \multirow{3}{*}{$\begin{array}{l}\text { Sun } \\
\text { protection }\end{array}$} & \multirow{3}{*}{$\begin{array}{l}\text { Daylight } \\
\text { management }\end{array}$} & \multicolumn{2}{|c|}{ Incandescent lamp } & \multicolumn{2}{|c|}{ Halogen lamp } \\
\hline & & \multicolumn{2}{|c|}{ Energy demand } & \multicolumn{2}{|c|}{ Energy demand } \\
\hline & & {$[\mathrm{kWh} / \mathrm{a}]$} & {$\left[\mathrm{kWh} /\left(\mathrm{a} \cdot \mathrm{m}^{2}\right)\right]$} & {$[\mathrm{kWh} / \mathrm{a}]$} & {$\left[\mathrm{kWh} /\left(\mathrm{a} \cdot \mathrm{m}^{2}\right)\right]$} \\
\hline \multicolumn{6}{|c|}{ North orientation } \\
\hline NP & NM & 1516.43 & 50.55 & 1326.88 & 44.23 \\
\hline MO & \multirow{2}{*}{$\mathrm{DC}$} & 1601.51 & 53.38 & 1401.32 & 46.71 \\
\hline $\mathrm{AO}$ & & 1377.76 & 45.93 & 1205.54 & 40.18 \\
\hline \multicolumn{6}{|c|}{ East and West orientation } \\
\hline NP & NM & 1515.95 & 50.53 & 1326.46 & 44.22 \\
\hline $\mathrm{MO}$ & \multirow{2}{*}{$\mathrm{DC}$} & 1519.99 & 50.67 & 1329.99 & 44.33 \\
\hline $\mathrm{AO}$ & & 1336.52 & 44.55 & 1169.46 & 38.98 \\
\hline \multicolumn{6}{|c|}{ South orientation } \\
\hline NP & NM & 1504.67 & 50.16 & 1316.59 & 43.89 \\
\hline MO & \multirow{2}{*}{ DC } & 1421.08 & 47.37 & 1243.44 & 41.45 \\
\hline $\mathrm{AO}$ & & 1275.65 & 42.52 & 1116.19 & 37.21 \\
\hline
\end{tabular}

Notes: NP - No sun protection; $\mathrm{MO}$ - Manually operated venetian blinds; AO - Automatically operated venetian blinds; NM - No light management; DC - Daylight depend controls 
Table 6. Energy demand of lighting systems with CFLs and luminaires with integrated LEDs

\begin{tabular}{|c|c|c|c|c|c|}
\hline \multirow{3}{*}{$\begin{array}{l}\text { Sun } \\
\text { protection }\end{array}$} & \multirow{3}{*}{$\begin{array}{l}\text { Daylight } \\
\text { management }\end{array}$} & \multirow{2}{*}{\multicolumn{2}{|c|}{$\frac{\text { Compact fluorescent lamp CFL }}{\text { Energy demand }}$}} & \multirow{2}{*}{\multicolumn{2}{|c|}{$\frac{\text { Luminaire with integrated LEDs }}{\text { Energy demand }}$}} \\
\hline & & & & & \\
\hline & & {$[\mathrm{kWh} / \mathrm{a}]$} & {$\left[\mathrm{kWh} /\left(\mathrm{a} \cdot \mathrm{m}^{2}\right)\right]$} & {$[\mathrm{kWh} / \mathrm{a}]$} & {$\left[\mathrm{kWh} /\left(\mathrm{a} \cdot \mathrm{m}^{2}\right)\right]$} \\
\hline \multicolumn{6}{|c|}{ North orientation } \\
\hline $\mathrm{NP}$ & NM & 398.06 & 13.27 & 272.96 & 9.10 \\
\hline $\mathrm{MO}$ & \multirow{2}{*}{$\mathrm{DC}$} & 420.40 & 14.10 & 288.27 & 9.61 \\
\hline $\mathrm{AO}$ & & 361.66 & 12.60 & 248.00 & 8.27 \\
\hline \multicolumn{6}{|c|}{ East and West orientation } \\
\hline NP & NM & 397.94 & 13.26 & 272.87 & 9.10 \\
\hline $\mathrm{MO}$ & \multirow{2}{*}{$\mathrm{DC}$} & 399.00 & 13.30 & 273.60 & 9.12 \\
\hline $\mathrm{AO}$ & & 350.84 & 11.96 & 240.57 & 8.20 \\
\hline \multicolumn{6}{|c|}{ South orientation } \\
\hline NP & NM & 394.98 & 13.17 & 270.84 & 9.30 \\
\hline $\mathrm{MO}$ & \multirow{2}{*}{$\mathrm{DC}$} & 373.03 & 12.43 & 255.79 & 8.53 \\
\hline $\mathrm{AO}$ & & 334.86 & 11.16 & 229.62 & 7.65 \\
\hline
\end{tabular}

Notes: NP - No sun protection; MO - Manually operated venetian blinds; AO - Automatically operated venetian blinds; NM - No light management; DC - Daylight depend controls

\section{Results}

\subsection{Incandescent and halogen lamps}

The installed power $800 \mathrm{~W}$ recalculated to per square meter is $26.67 \mathrm{~W} / \mathrm{m}^{2}$. This room is illuminated by 8 incandescent lamps with total luminous flux
$\Phi=10800 \mathrm{~lm}$. It was found that installed 24 halogen lamps requires installed power per square meter $23.33 \mathrm{~W} / \mathrm{m}^{2}$ and produce comparable luminous flux $\Phi=10500 \mathrm{~lm}$. Calculated energy demands for each scenario with incandescent and halogen lamps are documented in Table 5.

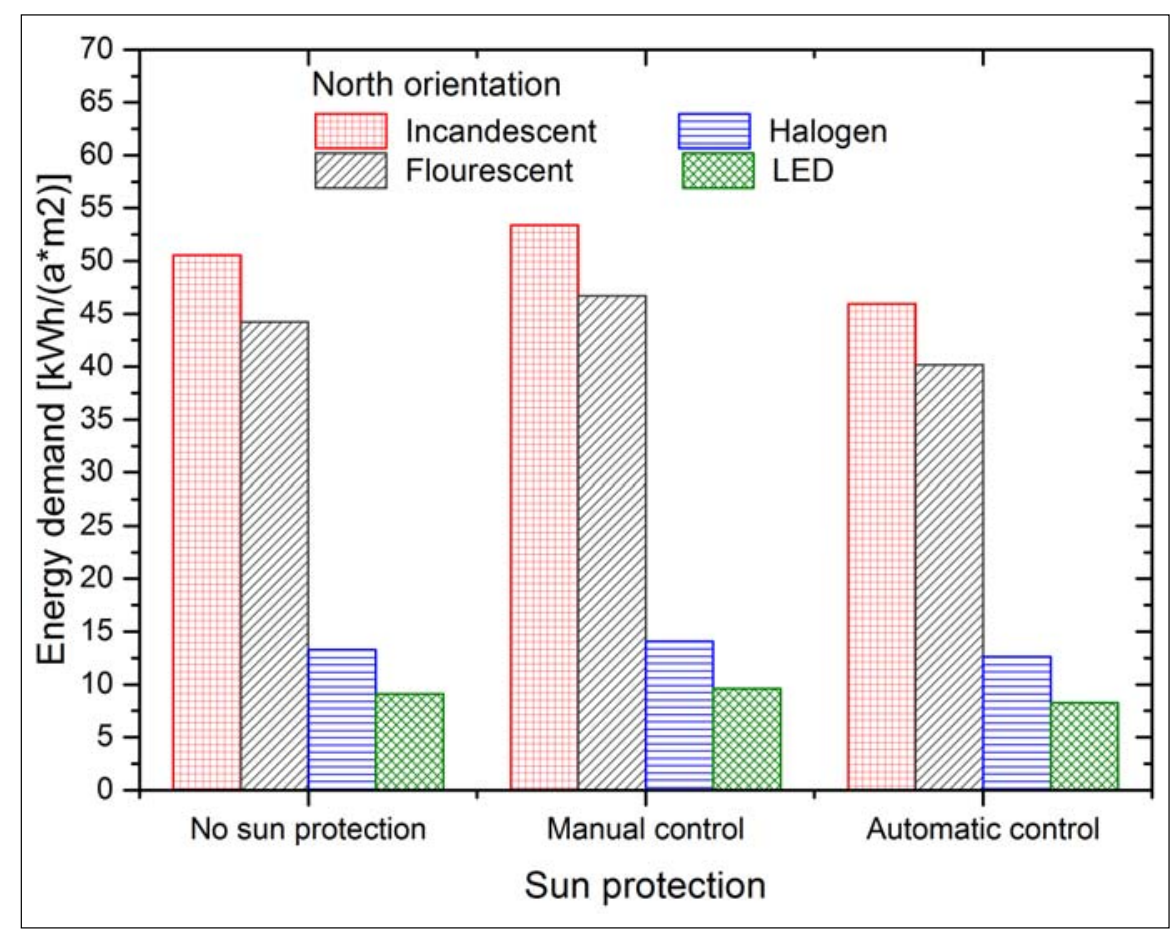

Fig. 1. Energy demand in the room oriented to North 


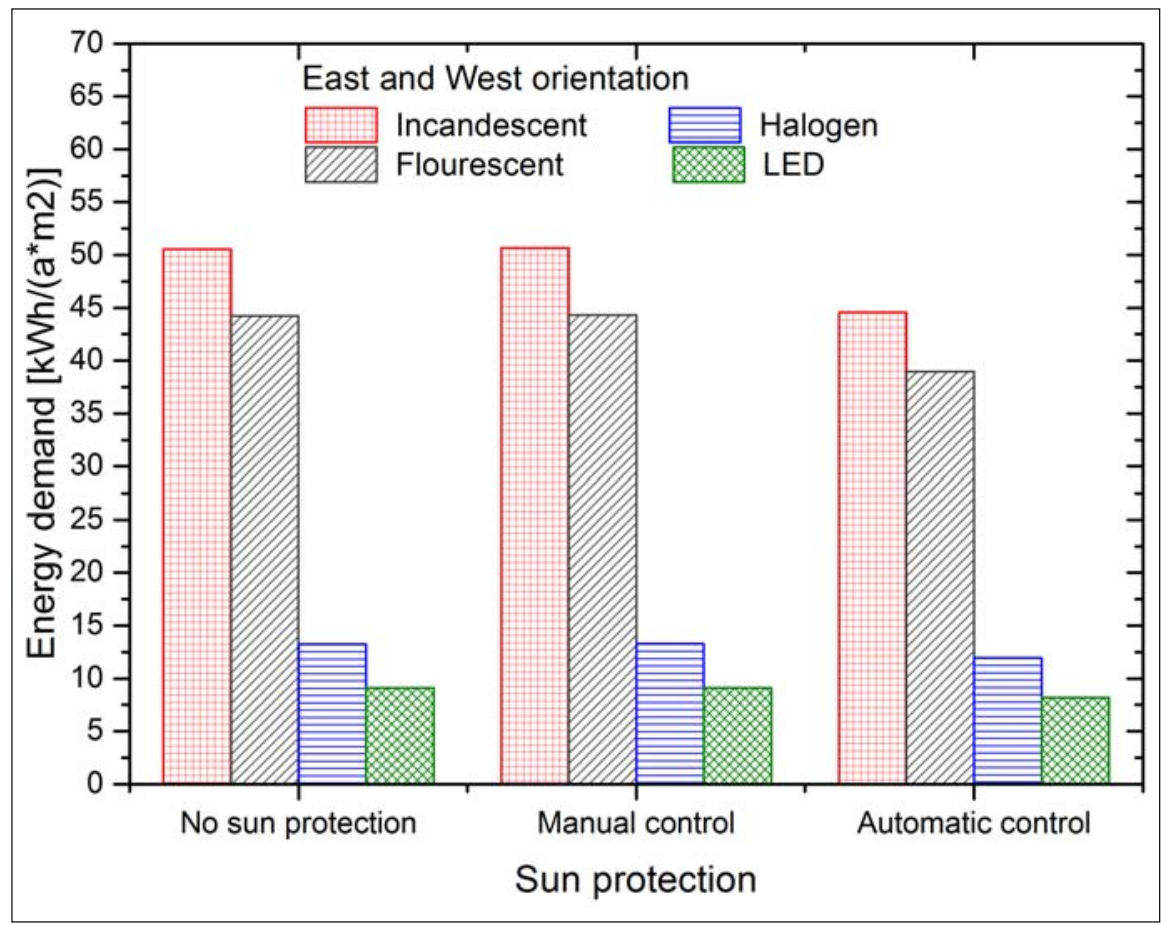

Fig. 2. Energy demand in the room oriented to East or West

\subsection{Compact fluorescent lamps CFL and luminaires with integrated LEDs}

Similar procedure was used to investigate total and recalculated energy demand per square meter in the office with compact fluorescent lamps CFL and lumi- naires with integrated LEDs. CFL light sources produce luminous flux $\Phi=11115 \mathrm{~lm}$ and require total installed power $210 \mathrm{~W}$, or otherwise power per square meter of office area calculated as $7.00 \mathrm{~W} / \mathrm{m}^{2}$. Luminaires with integrated LEDs with luminous efficacy eff $=62.5 \mathrm{~lm} / \mathrm{W}$ produce total luminous flux

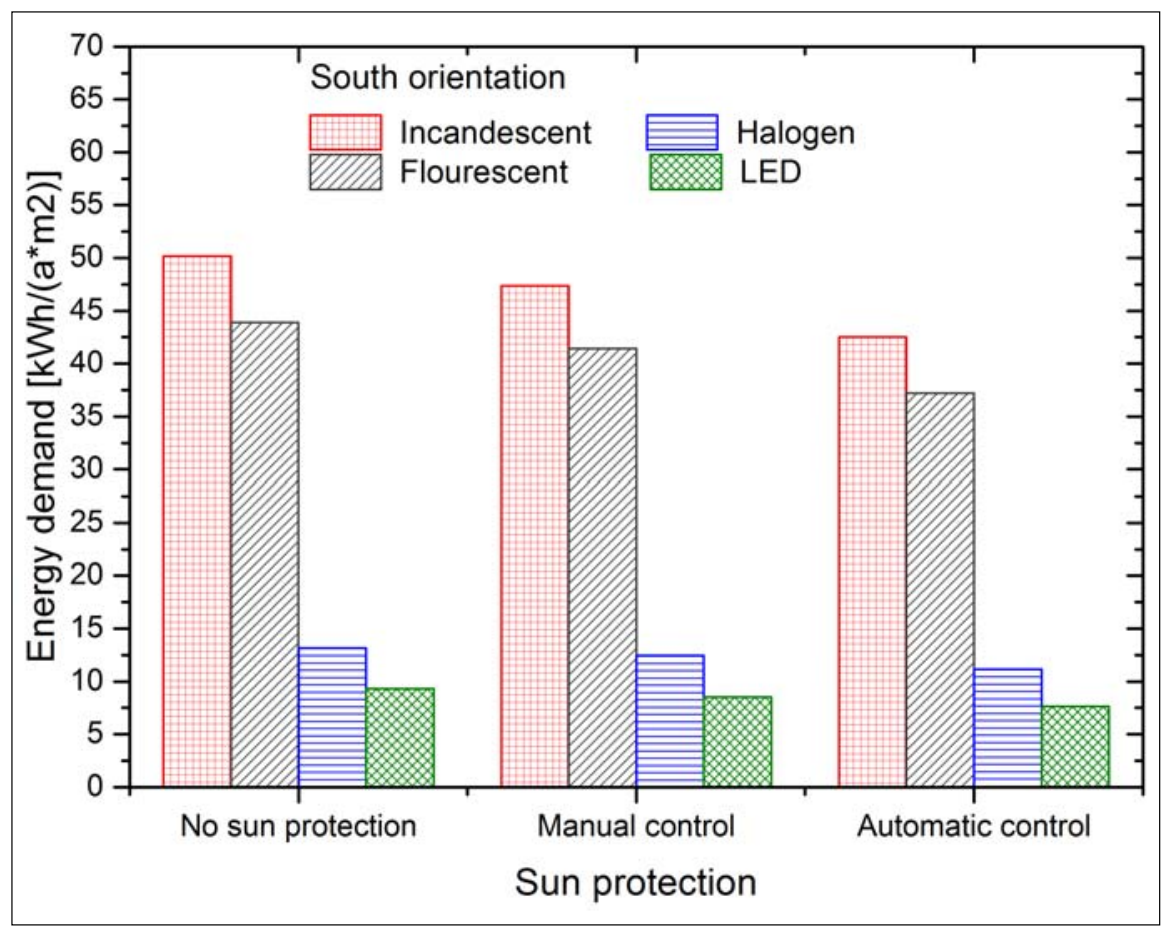

Fig. 3. Energy demand in the room oriented to South 
Table 7. Assessment of investigated scenarios

\begin{tabular}{|c|c|c|c|c|c|c|c|c|c|c|c|c|}
\hline \multirow[b]{3}{*}{ Indicator } & \multicolumn{3}{|c|}{ Incandescent } & \multicolumn{3}{|c|}{ Halogen } & \multicolumn{3}{|c|}{ CFL } & \multicolumn{3}{|c|}{ LED } \\
\hline & NP & MO & \multirow{2}{*}{$\mathrm{AO}$} & NP & MO & \multirow{2}{*}{$\mathrm{AO}$} & NP & $\mathrm{MO}$ & \multirow{2}{*}{$\mathrm{AO}$} & NP & $\mathrm{MO}$ & \multirow{2}{*}{$\mathrm{AO}$} \\
\hline & $\mathrm{NM}$ & $\mathrm{DC}$ & & NM & $\mathrm{DC}$ & & NM & $\mathrm{DC}$ & & NM & DC & \\
\hline$C C T$ & & 4 & & & 3 & & & 2 & & & 1 & \\
\hline Energy demand & 2 & 3 & 1 & 2 & 3 & 1 & 2 & 3 & 1 & 2 & 3 & 1 \\
\hline Sum & 6 & 7 & 5 & 5 & 6 & 4 & 4 & 5 & 3 & 3 & 4 & 2 \\
\hline
\end{tabular}

Notes: NP - No sun protection; MO - Manually operated venetian blinds; AO - Automatically operated venetian blinds; NM - No light management; DC - Daylight depend controls

$\Phi=10800 \mathrm{~lm}$. Calculated energy demands for each scenario with compact fluorescent lamps CFL and luminaires with integrated LEDs are presented in Table 6 .

Plotted energy demands $P$ expressed in $\mathrm{kWh} /$ $\left(a \cdot m^{2}\right)$ are presented in Figs 1 to 3. Diagrams show significant differences between applications of investigated light sources. Influence of room cardinal orientated is not such evident. Interesting result was found in comparison to sun protection in view of energy demand. The highest energy demand is observed in the case when manually operated venetian blinds probably due to adaptation of occupants to daylight changes and low frequency of shading system operation. The lowest energy demand was calculated for automatically operated venetian blinds.

The score 1-4 was applied for assessment of scenarios. The value 1 , very good, was assigned to the $C C T$ value, which is the closest to the $C C T$ of daylight. Score 1 was assigned to the most effective sun protection. The best solution for retrofit of investigated scenario (sum) is counted for lighting system consisting of luminaires with integrated LEDs and automatic operation of venetian blinds (score 2). The worst solution was found for scenario with incandescent lamps, manually operated sun protection and daylight dependent control management (score 7), Table 7.

\section{Discussion}

Currently, not only novel electric lighting for sufficient luminous environment is required but also the standard [10] creates pressure on the application of energy efficient technologies and lighting control management. Coupled use of daylighting and artificial lighting in the office spaces is one of the possibilities to create good environment.

Incandescent lamps are rather thermal source than source of illumination. New LED technologies make rapid development in colour rendering quality, energy efficiency and cost investment. In the next decades the wider utilization of daylight and LED sources with adaptive integrative lighting systems [11] and advanced digitalization will be dominant in the lighting engineering practice. Results of the presented study are also in the intention of this tendency. Ongoing European standard [12] creates conditions for the development and adoption of these new technologies.

When halogen sources were evaluated the energy savings effects around $12.5 \%$ can be expected (see Table 8). Correlated colour temperature of halogen sources creates an environment shifted a bit to daylight. Better results were achieved with scenarios based on compact fluorescent lamps - CFL. CCT of these sources is moved from warm to white and en-

Table 8. Effects of energy savings in \% considering sun protection

\begin{tabular}{llccc}
\hline \multirow{2}{*}{ Room orientation } & Light source & \multicolumn{3}{c}{ Sun protection } \\
\cline { 3 - 5 } & & No protection & Manual & Automat \\
\hline \multirow{3}{*}{ North } & Halogen & 12.50 & 12.50 & 12.52 \\
& CFL & 73.75 & 73.59 & 72.57 \\
& LED & 82.00 & 72.57 & 81.99 \\
\multirow{3}{*}{ East or West } & Halogen & 12.49 & 12.51 & 12.50 \\
& CFL & 73.76 & 73.75 & 73.15 \\
& LED & 81.99 & 82.00 & 81.59 \\
\multirow{3}{*}{ South } & Halogen & 12.50 & 12.50 & 12.49 \\
& CFL & 73.74 & 73.76 & 73.75 \\
& LED & 81.46 & 81.99 & 82.01 \\
\hline
\end{tabular}


ergy savings can rise to $73 \%$. The best results were obtained from scenarios using luminaires with white LED sources. CCT of these LED sources is in the range of $6500-7000 \mathrm{~K}$, quite close to daylight. LED technology brings the highest energy savings up to $82 \%$.

Advantage of incandescent lamps is in the simple replacement each to other and relatively low acquisition costs. Disadvantage of these sources is high energy consumption, low luminous efficacy, low life time and finishing production.

Halogen lamps create specific lighting conditions in interior because of separate rather spread lamps location in the ceiling. Compact fluorescent lamps are often used in office spaces because of reasonable energy savings, simple installation and maintenance. LED sources are perspective technology bringing high energy savings, good colour rendering in spaces and adaptation of this technology to digital control systems. Their disadvantage is in the one-time use without the possibility to replace the components.

\section{Conclusion}

A situation when the existing lighting system is obsolete, not economically sustainable and its function is out of user needs may arise any time. Owners of buildings have several possibilities to solve this situation. Depending on the budget the indoors lighting system can be completely reconstructed or upgraded. Retrofit of light sources, luminaires or their components is a solution which requires less investments, energy savings in artificial lighting operation and can give many benefits for occupants.

This study shows that the application of luminaires with CFL sources in office spaces with separately located work places can give a good-class visual environment and manage both daylighting and artificial lighting systems and it is energy efficient. The best energy savings were achieved with the application of white LED sources with correlated colour temperature close to daylight and automatic daylight control.

\section{Acknowledgements}

Authors are grateful for support of the Slovak research agency VEGA in the project VEGA 2/0042/17 and IEA SHC in the project IEA SHC Task 61.

\section{References}

[1] Dubois M. C. (2016), Building stock distribution and electricity use for lighting. A Technical Report of Subtask D, T50.D1, IEA SHC Task 50: Advanced Lighting Solutions for Retrofitting Buildings. Stuttgart, Germany: Fraunhofer-Institut für Bauphysik. p. 79.

[2] Ye X., Xia X., Zhang L., Zhu B. (2015), Optimal maintenance planning for sustainable energy efficiency lighting retrofit projects by a control system approach. Control Engineering Practice, 37, 110.

[3] Fabian M., Darula S. (2013), Vplyv zasklenia na zníženie potreby elektrickej energie na osvetlenie. (Influence of glazing on the electric energy reduction for lighting). Světlo, 16(5), 3841.

[4] Katunský D., Dolníkova E., Doroudiani S. (2017), Integrated lighting efficiency analysis in large industrial buildings to enhance indoor environmental quality. Buildings, 47(7), 120.

[5] Gasparovsky D., Raditschova J. (2013), Energy efficiency versus cost optimalization for lighting in buildings. Proceedings of the 12th European Lighting Conference LUX EUROPA, 2013 Sep 17-19; Cracow, Poland. PKO SEP, Warsaw, pp. 41-48.

[6] Sumpich J., Novak T., Carbol Z., Sokansky K. (2013), Calculation of saving possibilities in interior lighting system using both daylight and artificial light. Przeglad elektrotechniczny, 89(6), 345-347.

[7] Solmaz A. S., Halicioglu F. H. (2018), An approach for making optimal decisions in building energy efficiency retrofit projects. Indoor and Built Environment, 27(3), 348-368.

[8] Ab Halim M. F. M., Azlan U. Al-A., Harun M. H., Annuar K. A. M., Mustafa M., Johari S. H., Abdullah A. R., Hushim M. F. (2017), Lighting retrofit scheme economic evaluation. Indonesian Journal of Electrical Engineering and Computer Science, 5(3), 496-501.

[9] Darula S., Malikova M. (2015), IEA and lighting retrofit in buildings. Proceedings of the 21st International Conference LIGHT SVĚTLO, 2015; Brno, Czech Republic. FEEC Brno University of Technology, Brno, pp. 61-63.

[10] EN 15193 Energy performance of buildings - Energy requirements for Lighting.

[11] ISO/TC 274 N416 Strategic business plan. ISO/TC 274, 2018.

[12] FprEN 17037 Daylight in Buildings, 2018.

Web sources:

[Web 1] http://task50.iea-shc.org/

[Web 2] http://www.lightingretrofitadviser.com/ 